\title{
Trends in incidence and long-term prognosis of acute kidney injury following coronary angiography in Chinese cohort with 11,943 patients from 2013 to 2017: an observational study
}

Jin Liu ${ }^{1 \dagger}$, Qiang $\mathrm{Li}^{1+}$, Disheng Lai ${ }^{4 \dagger}$, Guoqin Chen ${ }^{6 \dagger}$, Bo Wang ${ }^{1 \dagger}$, Liwei Liu ${ }^{1,2}$, Haozhang Huang ${ }^{1,2}$, Zhubin Lun ${ }^{3}$, Ming Ying ${ }^{1}$, Guanzhong Chen ${ }^{1,4}$, Zhidong Huang ${ }^{1}$, Danyuan $\mathrm{Xu}^{1}$, Liangguang Meng ${ }^{1}$, Xiaoming Yan ${ }^{5}$, Weiyan Qiu', Ning Tan ${ }^{1,2,4}$, Jiyan Chen ${ }^{1,2,4}$, Yong Liu ${ }^{1,2,4^{*}}$ and Shiqun Chen ${ }^{1^{*}}$

\begin{abstract}
Background: Contrast-associated acute kidney injury (CA-AKI) is a common complication with poor prognosis after coronary angiography (CAG). With the prevention methods widely being implemented, the temporal trends of incidence and mortality of CA-AKI are still unknown over the last five years. The study aims to determine the incidence and prognosis of CA-AKI in China.

Methods: This retrospective cohort study was based on the registry at Guangdong Provincial People's Hospital in China (ClinicalTrials.gov NCT04407936). We analyzed data from hospitalization patients who underwent CAG and with preoperative and postoperative serum creatinine (Scr) values from January 2013 to December 2017.

Results: 11,943 patients were included in the study, in which the mean age was $63.01 \pm 10.79$ years and 8,469 $(71.1 \%)$ were male. The overall incidence of CA-AKI was $11.2 \%$. Compared with 2013, the incidence of CA-AKI in 2017 was significantly increased from 9.7 to $13.0 \%$ (adjusted odds ratios [aOR], 1.38; $95 \% \mathrm{Cl}, 1.13-1.68$; $P$-value < 0.01 , P for trend $<0.01$ ). The temporal trends of incidence among patients of different ages and genders yielded similar findings. During a standardized follow-up of 1 year, 178 (13.7\%) CA-AKI patients died in total, which showed no obvious decreased trend in this 5 five years from 21.1 to 16.5 (adjusted hazard ratio [aHR], 0.72; $95 \% \mathrm{Cl}, 0.36$ 1.45; $P$-value $=0.35, P$ for trend $=0.24$ ).
\end{abstract}

\footnotetext{
* Correspondence: liuyong@gdph.org.cn; shiqunchen@126.com

†Jin Liu, Qiang Li, Disheng Lai, Guoqin Chen and Bo Wang contributed equally to the manuscript.

'Department of Cardiology, Guangdong Provincial Key Laboratory of Coronary Heart Disease Prevention, Guangdong Provincial People's Hospital, Guangdong Cardiovascular Institute, Guangdong Academy of Medical Sciences, South China University of Technology, 510080 Guangzhou, China Full list of author information is available at the end of the article
}

C C The Author(s). 2021 Open Access This article is licensed under a Creative Commons Attribution 4.0 International License, which permits use, sharing, adaptation, distribution and reproduction in any medium or format, as long as you give appropriate credit to the original author(s) and the source, provide a link to the Creative Commons licence, and indicate if changes were made. The images or other third party material in this article are included in the article's Creative Commons licence, unless indicated otherwise in a credit line to the material. If material is not included in the article's Creative Commons licence and your intended use is not permitted by statutory regulation or exceeds the permitted use, you will need to obtain permission directly from the copyright holder. To view a copy of this licence, visit http://creativecommons.org/licenses/by/4.0/ The Creative Commons Public Domain Dedication waiver (http://creativecommons.org/publicdomain/zero/1.0/) applies to the data made available in this article, unless otherwise stated in a credit line to the data. 
Conclusions: Our Chinese cohort showed that the incidence of CA-AKI increased significantly, while CA-AKI associated mortality showed no obvious decreased trend in the last five years. Our findings support more active measures to prevent CA-AKI and improve the prognosis of CA-AKI patients.

Keywords: Contrast-associated acute kidney injury, Incidence, Trends, Mortality

\section{Background}

Contrast-associated acute kidney injury (CA-AKI) is a common complication after coronary angiography (CAG) and interventional procedures. It is significantly associated with increased short and long-term mortality [1-4].

Several prevention strategies such as intravenous infusion, contrast media volume limiting and assessments for the risk of CA-AKI were recommended to prevent CA-AKI [5-7]. These measures were confirmed effective in the meta-analysis and have been widely accepted and implemented in the last few years $[8,9]$.

However, it is unclear whether the incidence and mortality of CA-AKI have changed over the last five years. The study aims to determine the incidence and prognosis of CA-AKI in a large Chinese population who underwent CAG from 2013 to 2017.

\section{Method}

\section{Study design and population}

Thivs retrospective study was conducted at Guangdong Provincial People's Hospital in China (ClinicalTrials.gov NCT04407936). In total, 11,943 patients undergoing CAG and with preoperative and postoperative Scr values from January 2013 to December 2017 were included in this study.

The study was approved by the Guangdong Provincial People's Hospital ethics committee and the study was performed according to the declaration of Helsinki.

\section{Baseline data collection}

Data were extracted from the electronic Clinical Management System (CMS) of the Guangdong Provincial People's Hospital from January 2013 to December 2017. The collected baseline information included demographic characteristics, coexisting conditions, laboratory examinations and medications at discharge. Senior cardiologists were responsible for the data quality control and regular database check. CAG or percutaneous coronary intervention (PCI) was performed following standard clinical practice guidelines $[6,10,11]$.

\section{Clinical definition}

The estimated glomerular filtration rate (eGFR) was calculated by the Modification of Diet in Renal Disease (MDRD) formula [12]. Chronic kidney disease (CKD) was defined as eGFR $<60 \mathrm{~mL} / \mathrm{min} / 1.73 \mathrm{~mm}^{2}$. Coronary artery disease (CAD), Diabetes mellitus (DM) and hypertension were identified by the 10th Revision Codes of the International Classification of Diseases (ICD-10; I20.xx-I25.xx, I50.00001 and I91.40001, see Supplemental Table S1). Congestive heart failure (CHF) was defined as New York Heart Association (NYHA) class $>2$ or Killip class $>1$.

\section{Study outcome}

The primary endpoint of this study was CA-AKI which is defined as a serum Scr elevation $\geq 50 \%$ or $0.3 \mathrm{mg} / \mathrm{dL}$ from baseline within the first 48 to $72 \mathrm{~h}$ after the procedure [13]. The secondary endpoint was all-cause mortality in 1 year for patients with CA-AKI. Incident events were defined as the first event occurring between the date of enrollment and the end of follow-up of December 31, 2017. All participants were followed up by office visits or telephone interviews at 1 month, 6 months and 1 year after enrollment. Follow-up data was monitored and recorded by trained nurses through outpatient interviews and telephone.

\section{Statistical Analysis}

Patients were divided into 5 groups according to admission year. Descriptive statistics were reported as mean $\mathrm{SD}$, median (interquartile range [IQR]), or number and percentage when appropriate. The chi-square test was used to compare differences between categorical variables. The differences between the 5 groups were analyzed with one-way analysis of variance (ANOVA). Pearson chi-squared tests were used to analyze the categorical data.

We calculated the annual incidence of CA-AKI from 2013 to 2017. The mortality (per 1000 persons per year) during the 1-year follow-up period was used to assess the temporal trends of CA-AKI patients' prognosis. We used univariate and multivariate logistic regression analysis to estimate the odds ratio of CA-AKI between 2013 and 2017. Unadjusted and multivariable Cox proportional hazard regression analyses were used to explore the mortality temporal trends between 2013 and 2017. Model 1 and Model 4 were unadjusted; Model 2 and Model 5 were adjusted for age and gender; Model 3 was adjusted for age, gender, CMV, PCI, CHF and CKD; Model 6 was adjusted for multivariate variables including demographic (age, gender), medical history and procedural information (PCI, CHF, HT, DM and CKD) and 
medicine (ACEI/ARB, Beta-blocker). We graphically displayed unadjusted and adjusted odds ratios, hazard ratios and $95 \%$ confidence intervals for AKI over time.
Besides, we observed the trends of incidence and mortality for CA-AKI in different age $(\geq 65$ and $<65$ years old) and gender (male and female) subgroups. All data

Table 1 Characteristics of 11,943 patients undergoing coronary angiography

\begin{tabular}{|c|c|c|c|c|c|c|c|}
\hline Characteristic & $\begin{array}{l}\text { Overall } \\
(N=11,943)\end{array}$ & $\begin{array}{l}2013 \\
(N=2,459)\end{array}$ & $\begin{array}{l}2014 \\
(N=2,578)\end{array}$ & $\begin{array}{l}2015 \\
(N=2,824)\end{array}$ & $\begin{array}{l}2016 \\
(N=1,960)\end{array}$ & $\begin{array}{l}2017 \\
(N=2,122)\end{array}$ & $P$-value \\
\hline \multicolumn{8}{|l|}{ Demographic } \\
\hline Age, years & 63.01(10.79) & $63.23(10.81)$ & $63.24(10.93)$ & $62.42(10.75)$ & $63.51(10.70)$ & $62.77(10.68)$ & 0.003 \\
\hline Age $\geq 65(\%)$ & $5343(44.7)$ & $1116(45.4)$ & $1172(45.5)$ & $1222(43.3)$ & $917(46.8)$ & $916(43.2)$ & 0.068 \\
\hline Female, n (\%) & 3447 (28.9) & $712(29.0)$ & $743(28.8)$ & $834(29.5)$ & $503(25.7)$ & $655(30.9)$ & 0.006 \\
\hline \multicolumn{8}{|l|}{ Medical history } \\
\hline AMI, n (\%) & $2487(20.8)$ & $487(19.8)$ & $507(19.7)$ & $606(21.5)$ & $469(23.9)$ & $418(19.7)$ & 0.002 \\
\hline $\mathrm{CHF}, \mathrm{n}(\%)$ & 2575 (32.6) & $505(32.7)$ & $524(29.2)$ & $606(29.7)$ & $430(36.3)$ & $510(38.5)$ & $<0.001$ \\
\hline HT, n (\%) & $6363(53.3)$ & $1327(54.0)$ & $1426(55.3)$ & $1459(51.7)$ & $1095(55.9)$ & $1056(49.8)$ & $<0.001$ \\
\hline $\mathrm{DM}, \mathrm{n}(\%)$ & $3203(26.8)$ & $650(26.4)$ & $685(26.6)$ & $731(25.9)$ & $573(29.2)$ & $564(26.6)$ & 0.116 \\
\hline$A F, n(\%)$ & $1472(12.3)$ & $246(10.0)$ & $259(10.0)$ & $341(12.1)$ & $235(12.0)$ & $391(18.4)$ & $<0.001$ \\
\hline Pre-MI, n (\%) & $683(5.7)$ & $136(5.5)$ & $150(5.8)$ & $181(6.4)$ & $114(5.8)$ & $102(4.8)$ & 0.198 \\
\hline $\mathrm{PCl}, \mathrm{n}(\%)$ & $5486(45.9)$ & $1330(54.1)$ & $1381(53.6)$ & $1356(48.0)$ & $806(41.1)$ & $613(28.9)$ & $<0.001$ \\
\hline CKD, n (\%) & $3236(27.1)$ & $639(26.0)$ & $619(24.0)$ & $700(24.8)$ & $655(33.4)$ & $623(29.4)$ & $<0.001$ \\
\hline \multicolumn{8}{|l|}{ Laboratory test } \\
\hline $\mathrm{eGFR}, \mathrm{ml} / \mathrm{min} / 1.73 \mathrm{~m}^{2}$ & $75.40(30.25)$ & $76.83(39.40)$ & 77.84 (27.34) & $77.12(27.15)$ & $72.36(29.26)$ & $71.31(25.21)$ & $<0.001$ \\
\hline $\mathrm{WBC}, 10^{9} / \mathrm{L}$ & $8.05(2.80)$ & $8.16(2.90)$ & $8.01(2.68)$ & $8.07(2.75)$ & $8.11(2.82)$ & $7.90(2.87)$ & 0.021 \\
\hline $\mathrm{HGB}, \mathrm{g} / \mathrm{L}$ & $130.41(18.45)$ & 131.37 (18.09) & $130.20(18.30)$ & $131.10(17.65)$ & $129.84(19.17)$ & $129.15(19.27)$ & $<0.001$ \\
\hline $\mathrm{CHOL}, \mathrm{mmol} / \mathrm{L}$ & $4.50(1.20)$ & $4.54(1.18)$ & $4.49(1.20)$ & $4.54(1.17)$ & $4.48(1.21)$ & $4.45(1.27)$ & 0.061 \\
\hline TRIG, mmol/L & $1.65(1.14)$ & $1.65(1.10)$ & $1.59(1.11)$ & $1.68(1.18)$ & $1.69(1.14)$ & $1.64(1.14)$ & 0.032 \\
\hline $\mathrm{LDLC}, \mathrm{mmol} / \mathrm{L}$ & $2.83(0.98)$ & $2.85(1.03)$ & $2.71(1.00)$ & $2.78(0.97)$ & $2.89(0.91)$ & $2.95(0.94)$ & $<0.001$ \\
\hline $\mathrm{HDLC}, \mathrm{mmol} / \mathrm{L}$ & $1.00(0.26)$ & $1.00(0.26)$ & $0.99(0.26)$ & $1.01(0.28)$ & $0.98(0.25)$ & $1.01(0.27)$ & $<0.001$ \\
\hline $\mathrm{HbA} 1 \mathrm{c}, \%$ & $6.42(1.33)$ & $6.52(1.35)$ & $6.40(1.29)$ & $6.33(1.27)$ & $6.50(1.43)$ & $6.39(1.37)$ & $<0.001$ \\
\hline Pre-scr, mmol/l & 106.59 (89.82) & $102.65(78.24)$ & $100.34(72.36)$ & $103.28(89.45)$ & $116.41(99.48)$ & $114.10(109.32)$ & $<0.001$ \\
\hline Scr-peak, mmol/l & 110.09 (86.10) & $105.87(77.78)$ & $104.75(75.60)$ & $108.19(81.43)$ & 116.95 (98.22) & $117.62(99.45)$ & $<0.001$ \\
\hline $\mathrm{CMV}, \mathrm{ml}$ & $142.26(97.69)$ & 149.37 (102.36) & $140.70(92.40)$ & 134.79 (94.34) & 149.08 (103.06) & 139.50 (97.44) & $<0.001$ \\
\hline \multicolumn{8}{|l|}{ Contrast medium, n (\%) } \\
\hline lopromide & $4468(40.6)$ & $1067(43.4)$ & $873(33.9)$ & $1073(39.9)$ & $724(44.2)$ & $731(44.2)$ & $<0.001$ \\
\hline lopamidol & $5920(53.8)$ & $1384(56.3)$ & $1554(60.3)$ & $1356(50.5)$ & $781(47.7)$ & $845(51.2)$ & $<0.001$ \\
\hline lodixanol & $1541(14.0)$ & $261(10.6)$ & $425(16.5)$ & $431(16.0)$ & $245(15.0)$ & $179(10.8)$ & $<0.001$ \\
\hline loversol & $319(2.9)$ & $2(0.1)$ & $33(1.3)$ & $104(3.9)$ & $86(5.3)$ & $94(5.7)$ & $<0.001$ \\
\hline lohexol & $147(1.3)$ & $62(2.5)$ & $24(0.9)$ & $23(0.9)$ & $15(0.9)$ & $23(1.4)$ & $<0.001$ \\
\hline \multicolumn{8}{|l|}{ Medication } \\
\hline ACEI/ARB, n (\%) & $6749(58.8)$ & $1466(62.4)$ & $1472(59.5)$ & $1563(57.6)$ & $1129(59.8)$ & $1119(54.5)$ & $<0.001$ \\
\hline Beta-blocker, n (\%) & $7245(63.0)$ & $1419(60.0)$ & $1519(61.4)$ & $1672(61.6)$ & 1239 (65.6) & $1396(68.0)$ & $<0.001$ \\
\hline Statin, n (\%) & 8801 (76.6) & $1868(79.0)$ & $1958(79.2)$ & $2042(75.2)$ & $1490(78.9)$ & $1443(70.3)$ & $<0.001$ \\
\hline Dialysis, n (\%) & $393(3.3)$ & $71(2.9)$ & $65(2.5)$ & $82(2.9)$ & $92(4.7)$ & $83(3.9)$ & $<0.001$ \\
\hline Discharge status ${ }^{\mathrm{a}}, \mathrm{n}(\%)$ & $197(1.6)$ & $44(1.8)$ & $37(1.4)$ & $42(1.5)$ & $29(1.5)$ & $45(2.1)$ & $<0.001$ \\
\hline
\end{tabular}

Abbreviation: $A M I$ acute myocardial infarction; $C H F$ congestive heart failure; $H T$ hypertensive; $D M$ diabetes mellitus; $A F$ atrial fibrillation; Pre-MI Previous myocardial infarction; PCI percutaneous coronary intervention; eGFR estimated glomerular filtration rate; WBC white blood cell; HGB hemoglobin; $C H O L$ total cholesterol; TRIG triglyceride; LDL-C low-density lipoprotein cholesterol; HDL-C high-density lipoprotein cholesterol; HbA1c hemoglobin A1c; Pre-scr Preoperative serum creatinine; Peak-scr Postoperative peak serum creatinine; CMV Contrast medium volume; ACEI/ARB angiotensin-converting enzyme inhibitor/angiotensin receptor blocker an-hospital death /Automatic discharge 
analyses were performed using $\mathrm{R}$ version 3.6.3 ( $\mathrm{R}$ Core Team, Vienna, Austria). All P values $<0.05$ were considered to represent statistical significance.

\section{Result}

\section{Clinical characteristics}

A total of 11,943 patients who underwent CAG were included in the study from January 2013 to December 2017. The baseline clinical characteristics of the patients were showed in Table 1 . Overall, the mean age was $63.01 \pm 10.79$ years, and 8,469 $(71.1 \%)$ were male.

Among patients undergoing coronary angiography, 5, 846 (45.9\%) patients underwent PCI treatment, CKD in $27.1 \%$ of the patients, and DM in $26.8 \%$. In these five years, the patients diagnosed with CHF increased $5.9 \%$ (from 32.6 to $38.5 \%$ ) and CKD increased $3.3 \%$ (from 27.1 to $29.4 \%$ ). The prevalence of HT has decreased by $3.5 \%$ (from 53.3 to $49.8 \%$ ) while there was no significant change in the prevalence of DM (from 26.8 to $26.6 \%$ ).

\section{Trends in the incidence of CA-AKI}

From January 2013 to December 2017, 1335 (11.2 \%) patients developed with CA-AKI. Compared with 2013, the incidence of CA-AKI in 2017 was significantly increased from 9.7 to $13.0 \%$ (adjusted odds ratios [aOR], 1.38; $95 \%$ CI, $1.13-1.68$; $P$ value $<0.01$, $P$ for trend $<0.01$ ). (Fig. 1; Table 2).

\section{Trends of 1-year all-cause mortality among CA-AKI patients}

During a follow-up of 1 year, 178 (13.7\%) CA-AKI patients died in total. Our data showed no obvious variation trend in this 5 five years, from 21.1 to 16.5 per 1 ,
000 person-years (adjusted hazard ratio [aHR], 0.72; $95 \% \mathrm{CI}, 0.36-1.45 ; \quad P$-value $=0.35, \mathrm{P}$ for trend $=0.24$ ) (Fig. 1; Table 2).

\section{Subgroups analyses}

Eight hundred seventy-two (10.3\%) patients who complicated with CA-AKI were men whereas 463 (13.4\%) were women. The incidence of CA-AKI showed an upward trend in both groups (male: 8.5 to 12.1 per 1,000 person-year, $\mathrm{P}$ for trend $<0.01$; female: 12.6 to 15.1 per 1 , 000 person-year, $\mathrm{P}$ for trend $=0.03, \mathrm{P}$ for interaction $=$ 0.99, see Fig. 2 A).

There were 134 (15.2\%) all-cause death in men and 44 $(9.8 \%)$ in women during 1 year among patients with CA-AKI. On the whole, the mortality of both groups showed a downward trend over 5 years (male: 19.6 to 15.6 per 1,000 person-year, $\mathrm{P}$ for trend $=0.55$; female: 13.6 to 9.7 per 1,000 person-year, $\mathrm{P}$ for trend $=0.80, \mathrm{P}$ for interaction $=0.95$, see Fig. $2 B$ ).

From 2013 to 2017, 626 (11.7\%) patients developed CA-AKI in patients older than 65 years and $709(10.7 \%)$ in patients age $<65$ years. The risk of CA-AKI in the two age groups showed an upward trend (male: 10.6 to 14.7 per 1,000 person-year, $\mathrm{P}$ for trend $=0.01$; female: 8.9 to 11.7 per 1,000 person-year, $\mathrm{P}$ for trend $<0.01$, $\mathrm{P}$ for interaction $=0.96$, see Fig. 2 C).

All-cause death in CA-AKI patients older than 65 years was $126(20.6 \%)$, and $52(7.5 \%)$ in patients age $<65$ years. On the other hand, the mortality showed a downward trend in patients older than 65 years while showed an upward trend in patients age $<$ 65 years ( $\geq 65$ group, 28.2 to 16.4 per 1,000 personyear, $\mathrm{P}$ for trend $=0.08$; < 65 group, 6.7 to 10.6 per 1 ,

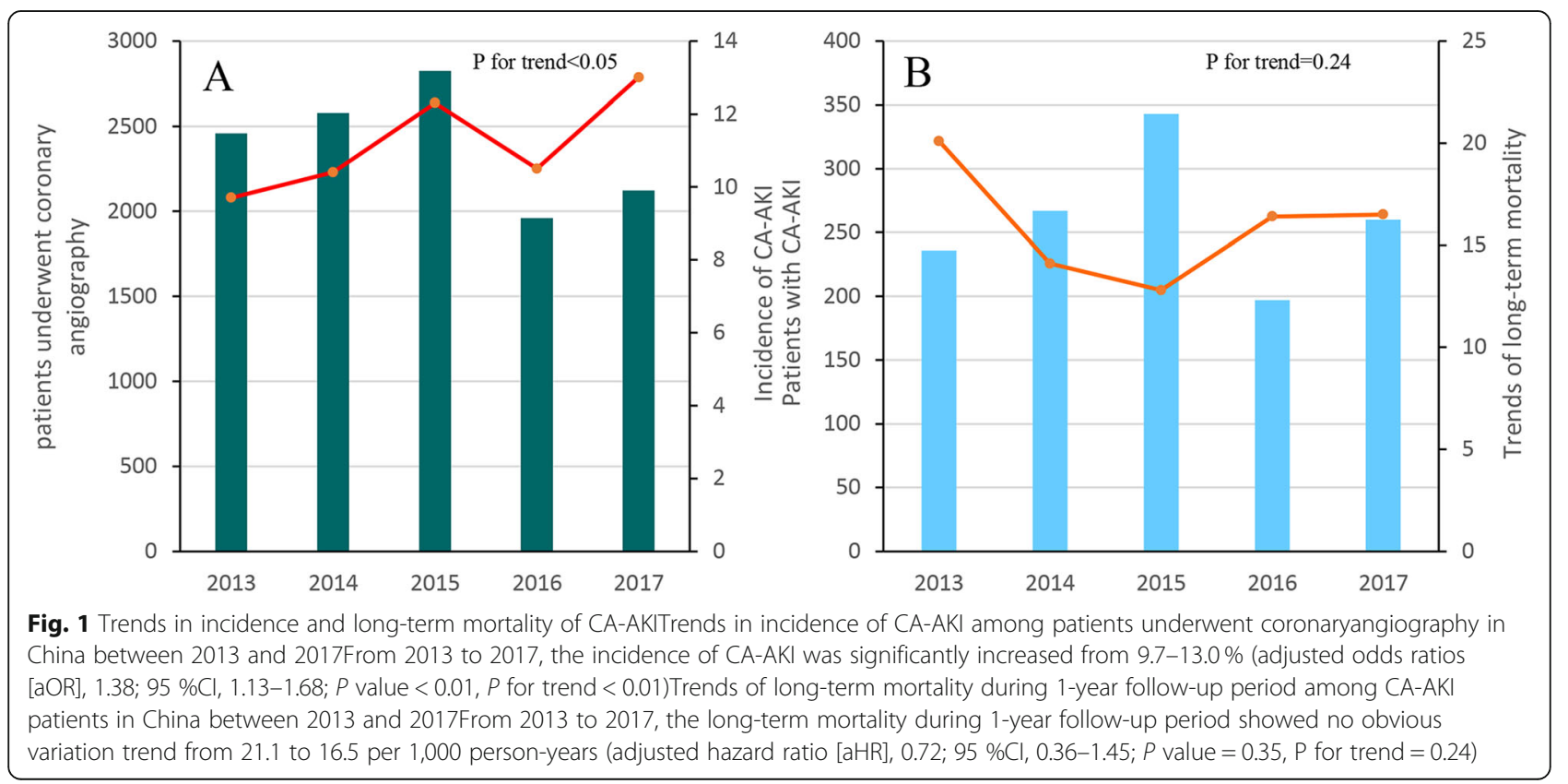


Table 2 Odds Ratios for prevalence and Hazard Ratios for Mortality between 2013 and 2017

\begin{tabular}{|c|c|c|c|}
\hline Years & Odds Ratios & $P$-value & $P$ for trend \\
\hline \multicolumn{4}{|l|}{ Model 1} \\
\hline 2013 & 1 (reference) & - & $<0.01$ \\
\hline 2014 & $1.09(0.90-1.31)$ & 0.38 & \\
\hline 2015 & $1.31(1.10-1.56)$ & $<0.01$ & \\
\hline 2016 & $1.14(0.93-1.39)$ & 0.2 & \\
\hline 2017 & $1.45(1.20-1.75)$ & $<0.01$ & \\
\hline \multicolumn{4}{|l|}{ Model 2} \\
\hline 2013 & 1 (reference) & - & $<0.01$ \\
\hline 2014 & $1.09(0.90-1.31)$ & 0.38 & \\
\hline 2015 & $1.31(1.10-1.56)$ & $<0.01$ & \\
\hline 2016 & $1.15(0.94-1.41)$ & 0.17 & \\
\hline 2017 & $1.48(1.20-1.75)$ & $<0.01$ & \\
\hline \multicolumn{4}{|l|}{ Model 3} \\
\hline 2013 & & - & $<0.01$ \\
\hline 2014 & $1.09(0.91-1.32)$ & 0.35 & \\
\hline 2015 & $1.32(1.10-1.58)$ & $<0.01$ & \\
\hline 2016 & $1.06(0.86-1.31)$ & 0.59 & \\
\hline 2017 & $1.38(1.13-1.68)$ & $<0.01$ & \\
\hline Years & Hazard Ratios & $P$ value & P for trend \\
\hline \multicolumn{4}{|l|}{ Model 4} \\
\hline 2013 & 1 (reference) & - & 0.52 \\
\hline 2014 & $0.71(0.45-1.12)$ & 0.14 & \\
\hline 2015 & $0.65(0.42-1.01)$ & 0.05 & \\
\hline 2016 & $0.82(0.50-1.32)$ & 0.4 & \\
\hline 2017 & $0.80(0.51-1.26)$ & 0.34 & \\
\hline \multicolumn{4}{|l|}{ Model 5} \\
\hline 2013 & 1 (reference) & - & 0.42 \\
\hline 2014 & $0.70(0.44-1.10)$ & 0.12 & \\
\hline 2015 & $0.66(0.42-1.02)$ & 0.06 & \\
\hline 2016 & $0.81(0.50-1.31)$ & 0.4 & \\
\hline 2017 & $0.76(0.48-1.19)$ & 0.23 & \\
\hline \multicolumn{4}{|l|}{ Model 6} \\
\hline 2013 & & - & 0.24 \\
\hline 2014 & $0.77(0.39-1.52)$ & 0.45 & \\
\hline 2015 & $0.56(0.28-1.13)$ & 0.1 & \\
\hline 2016 & $0.52(0.22-1.23)$ & 0.13 & \\
\hline 2017 & $0.72(0.36-1.45)$ & 0.35 & \\
\hline
\end{tabular}

Model 1 and Model 4: unadjusted

Model 2 and Model 5: adjusted for age and gender

Model 3: adjusted for multivariate variables (age, gender, $\mathrm{CMV}, \mathrm{PCl}, \mathrm{CHF}$ and (KD)

Model 6: adjusted for multivariate variables (age, gender, $\mathrm{PCI}, \mathrm{CKD}, \mathrm{HT}$, DM CHF, ACEI/ARB and Beta-blocker)
000 person-year, $\mathrm{P}$ for trend $=0.20$; $\mathrm{P}$ for interaction $<$ 0.05, see Fig. 2D).

\section{Discussion}

To the best of our knowledge, this is the first study to explore the trends in incidence and long-term mortality of CA-AKI in the last five years. Our data suggests that the incidence of CA-AKI was $11.2 \%$ and showed an upward trend from 2013 to 2017. Meanwhile, the findings indicate that CA-AKI associated mortality was $13.7 \%$ and was not significantly decreased.

In our cohort, the incidence of CA-AKI was $9.7-12 \%$ between 2013 and 2017, which was similar to the previous study regarding patients undergoing selected or emergent procedures. The incidence of CA-AKI has been reported to approximately range from 7.0 to $22.7 \%$ [14-16]. Direct and indirect effects, as well as hemodynamic perturbations, were considered to be the main mechanisms of kidney injury caused by contrast agents. Direct mechanisms of kidney injury from exposure to contrast agents were considered to be due to nephrotoxic effects on the tubular epithelial cells, leading to the loss of cell function, apoptosis, and eventually, necrosis. The indirect mechanisms were related to ischemic damage caused by vasomotor changes mediated by vasoactive substances such as endothelin, nitric oxide and prostaglandin [3].

Our study indicated that the incidence of CA-AKI has showed an upward trend in recent years. Khera et al. found that the incidence of AKI manifested an upward trend in patients $\geq 75$ years with acute myocardial infarction and undergoing primary percutaneous coronary intervention treatment from 2002 to 2010 [15]. Although that study just focused on the acute myocardial infarction subgroup among CAD populations, it has similar trends with our study.

The dose of contrast agent showed a downward trend in the last five years, while the incidence of CA-AKI showed an upward trend. There were several possible explanations for the trends towards the increased incidence of CA-AKI. First, clinicians have paid more attention to CA-AKI in recent years. Risk assessment and hydration were recommended and were proved to be effective preventive measures for CA-AKI [7, 16-18]. Increased attention to CA-AKI has resulted in more patients being evaluated, such as post-operative testing for Scr. In the past, some patients may develop CI-AKI, but postoperative creatinine was not detected, which made some patients complicated with CA-AKI be ignored. Physicians would take more preventive or curative treatments for CA-AKI among high-risk patients, which may decrease the CA-AKI associated mortality. Second, Mehran et al. indicated that CHF and CKD were the risk factors for CA-AKI [18]. In this large population 

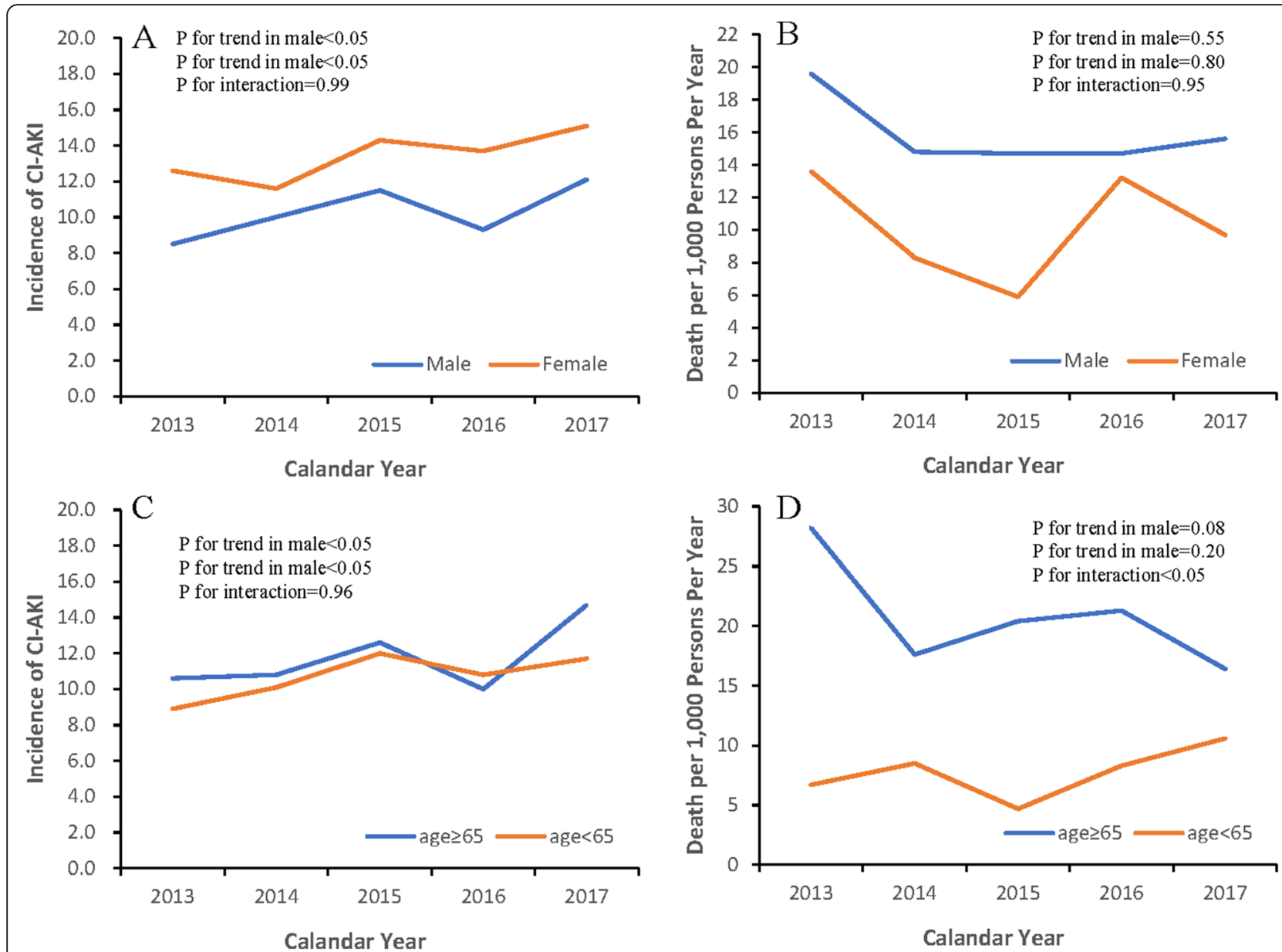

Fig. 2 Trends in incidence and long-term mortality of 4 different Subgroups between 2013 and 2017A. Trends in incidence of CA-AKI among male ( $P$ for trend $<0.01$ ) and female $(P$ for trend $=0.03)$;B. Trends of 1 -year mortality per 1,000 person-year among male $(P$ for trend $=0.55)$ and female ( $P$ for trend $=0.80)$;C. Trends in incidence of $C A$-AKl among $<65$ years group $(P$ for trend $=0.01)$ and $\geq 65$ years group $(P$ for trend $<0.01)$; D. Trends of 1-year mortality per 1,000 person-year among $<65$ years group $(P$ for trend $=0.08)$ and $\geq 65$ years group $(P$ for trend $=0.20)$

cohort, the proportion of CHF, anemia and CKD were showed obvious trends of escalation, and the risk of CAAKI among CAG patients increased.

We found that in patients of different ages and genders, the incidence of CA-AKI has shown an upward trend in the last five years (P-value for interaction > 0.05). But in patients of different ages, CA-AKI associated mortality shows different trends. The mortality showed a downward trend in patients older than 65 years while showed an upward trend in patients age $<$ 65 years ( $\mathrm{P}$ for interaction $<0.05$ ). The possible reason is that in clinical practice, elderly patients are more likely to get attention after they develop CA-AKI. Doctors will take a variety of methods to treat this disease including intravenous hydration, sodium bicarbonate, acetylcysteine, and renal replacement therapy. In young patients, the slight decline in renal function after CAG is often ignored without further renal function monitoring and treatment, which leads to long-term kidney damage, even death. This reminds us that we should pay enough attention to CA-AKI, regardless of whether it is in elderly or young patients.

Many preventive measures have been proposed to prevent CA-AKI. Hydration has proven to be a very important and effective measure, which was recommended in the 2013 and 2014 clinical guidelines [19, 20]. Most of the patients included in the study received routine intravenous hydration pre- and post-CAG according to routine clinical practice. Despite receiving regular hydration, we find the incidence and mortality of CA-AKI have not been improved very well during the past five years. Due to the lack of data on the volume and the rate of hydration, we cannot further analyze the impact of hydration on CA-AKI. This is worthy of further exploration in future research.

We found that patients who underwent CAG tended to have renal function decline even dialysis. This is 
consistent with the findings of James MT et al. [21]. But in our cohort, patients who underwent CAG were more likely to have dialysis $(3.3 \%)$ after the procedure than in previous studies which the rate of dialysis range from 1.0 to $2.7 \%[17,22]$. Compared with these studies, the patients in our study had worse baseline renal function and more complications. At the same time, these studies are all about venous hydration, the patients included in the study have received different schemes of venous hydration, which can help to reduce the risk of postoperative dialysis. Therefore, routine venous hydration and risk assessment are helpful to reduce the risk of postoperative dialysis and CA-AKI for patients undergoing CAG.

Our data suggested that CA-AKI is still a serious complication after intervention treatment. It is necessary to strengthen the prevention treatments among patients at high risk of CA-AKI, especially in CKD, elder and heart failure populations. We should strengthen the mechanism research of CA-AKI to explore more effective strategies and agents for the prevention of CA-AKI among patients undergoing CAG.

\section{Limitation}

Our study has some limitations. First, the cohort was conducted in a single center located in south China. However, Guangdong Provincial People's Hospital represents the high-level unit especially in the cardiovascular direction, hence our study involved abundant patients from different regions, and most of the patients complicated with different risk factors, which made the results more generalizable. Second, our cohort only included people who underwent CAG and lacked information about people who were exposed to intravenous contrast agents. Whereas the incidence of CA-AKI in CAG is significantly higher than that of intravenous contrast agents. Therefore, we should pay more attention to patients undergoing CAG. Third, we only used serum Scr elevation $\geq 25 \%$ or $0.5 \mathrm{mg} / \mathrm{dL}$ from baseline within the first 48 to $72 \mathrm{~h}$ after the procedure to define CA-AKI. However, this definition has reasonable sensitivity and is widely recommended and used internationally. Fourth, this dataset lack off several information about the stage of AKI, shock events, emergent/urgent CAG or elective CAG, and the volume intravenous hydration, but we have considered several relevant variables and shown in Table 1, such as acute myocardial infarction (AMI).

\section{Conclusions}

This study demonstrated that the incidence of CA-AKI was significantly increased, while the CA-AKI associated mortality showed no obvious decreased trend in the last five years. These findings highlighted that CA-AKI is still an important public health problem in China. Further research would need to explore more strategies to decrease the incidence of CA-AKI and improve the prognosis of CA-AKI patients.

\begin{abstract}
Abbreviations
ANOVA: One-way analysis of variance; CA-AKI: Contrast-associated acute kidney injury; CAD: Coronary artery disease; CAG: coronary angiography; CHF: Congestive heart failure; CKD: Chronic kidney disease; CMS: Clinical Management System; DM: Diabetes mellitus; eGFR: Estimated glomerular filtration rate; MDRD: Modification of Diet in Renal Disease; NYHA: New York Heart Association; PCl: Percutaneous coronary intervention
\end{abstract}

\section{Supplementary Information}

The online version contains supplementary material available at https://doi. org/10.1186/s12882-021-02427-6.

Additional file 1.

\section{Acknowledgements}

Special thanks to Professor Ying Xian (Duke Clinical Research Institute, Durham, NC, 27705, USA) for helping with the study design. We thank Dr. Buyun Liu for her precious comments. This study was supported by grants from National Key Research and Development Program of China, Grant (2016YFC1301202). We are grateful for the support of this program and its funds

Authors' contributions

Research idea and study design: SQC, YL, JL, NT and JYC; Data acquisition: J QL DSL GQC BW LWL HZH ZBL MY CZC ZDH XMY and WYQ; Data analysis/ interpretation: JL, SQC; Statistical analysis: DYX, LGM; Supervision and mentorship: SQC, YL, JYC, NT; Writing guidance: YX and BYL. Each author contributed important intellectual content during manuscript drafting or revision and accepts accountability for the overall work by ensuring that questions pertaining to the accuracy or integrity of any portion of the work are appropriately investigated and resolved. The author(s) read and approved the final manuscript.

\section{Funding}

This study was supported by grants from National Key Research and Development Program of China, Grant (2016YFC1301202), Guangdong Provincial People's Hospital Dengfeng Project Fund (DFJH201919) and The National Science Foundation for Young Scientist of China (grant no.8197021596, 81500520). The funders had no role in the study design, data collection and analysis, decision to publish, or preparation of the manuscript; the work was not funded by any industry sponsors.

\section{Availability of data and materials}

The datasets used and/or analyzed during the current study are available from the corresponding author on reasonable request.

\section{Declarations}

Ethics approval and consent to participate

This study protocol was approved by the Guangdong Provincial People's Hospital ethics committee and the study was performed according to the declaration of Helsinki. The need of waived informed consent approved by Guangdong Provincial People's Hospital ethics committee.

Consent for publication

Not applicable.

\section{Competing interests}

The author declares that they have no competing interests.

\section{Author details}

${ }^{1}$ Department of Cardiology, Guangdong Provincial Key Laboratory of

Coronary Heart Disease Prevention, Guangdong Provincial People's Hospital, 
Guangdong Cardiovascular Institute, Guangdong Academy of Medical Sciences, South China University of Technology, 510080 Guangzhou, China. ${ }^{2}$ The Second School of Clinical Medicine, Southern Medical University, 510515 Guangzhou, China. ${ }^{3}$ Department of Cardiology, Dongguan TCM Hospital, 523209 Dongguan, China. ${ }^{4}$ Guangdong Provincial People's Hospital, School of Medicine, South China University of Technology, 510100 Guangzhou, China. ${ }^{5}$ Department of Information Technology, Guangdong Provincial People's Hospital, Guangdong Academy of Medical Sciences, 510080 Guangzhou, China. ${ }^{6}$ Department of Cardiology, Guangzhou Panyu Central Hospital, Guangzhou, China.

\section{Received: 22 November 2020 Accepted: 28 May 2021}

Published online: 25 June 2021

\section{References}

1. Narula A, Mehran R, Weisz G, Dangas GD, Yu J, Généreux P, Nikolsky E, Brener SJ, Witzenbichler B, Guagliumi G et al: Contrast-induced acute kidney injury after primary percutaneous coronary intervention: results from the HORIZONS-AMI substudy. Eur Heart J 2014, 35(23):1533-1540.

2. Wickenbrock I, Perings C, Maagh P, Quack I, van Bracht M, Prull MW, Plehn G, Trappe HJ, Meissner A: Contrast medium induced nephropathy in patients undergoing percutaneous coronary intervention for acute coronary syndrome: differences in STEMI and NSTEMI. Clinical research in cardiology: official journal of the German Cardiac Society 2009, 98(12):765-772.

3. Mehran R, Dangas GD, Weisbord SD: Contrast-Associated Acute Kidney Injury. N Engl J Med 2019, 380(22):2146-2155.

4. Yang Y, George KC, Luo R, Cheng Y, Shang W, Ge S, Xu G: Contrast-induced acute kidney injury and adverse clinical outcomes risk in acute coronary syndrome patients undergoing percutaneous coronary intervention: a metaanalysis. BMC Nephrol 2018, 19(1):374.

5. Wright RS, Anderson JL, Adams CD, Bridges CR, Casey DE, Jr., Ettinger SM, Fesmire FM, Ganiats TG, Jneid H, Lincoff AM et al: 2011 ACCF/AHA focused update of the Guidelines for the Management of Patients with Unstable Angina/Non-ST-Elevation Myocardial Infarction (updating the 2007 guideline): a report of the American College of Cardiology Foundation/ American Heart Association Task Force on Practice Guidelines developed in collaboration with the American College of Emergency Physicians, Society for Cardiovascular Angiography and Interventions, and Society of Thoracic Surgeons. J Am Coll Cardiol 2011, 57(19):1920-1959.

6. Levine GN, Bates ER, Blankenship JC, Bailey SR, Bittl JA, Cercek B, Chambers CE, Ellis SG, Guyton RA, Hollenberg SM et al: 2015 ACC/AHA/SCAl Focused Update on Primary Percutaneous Coronary Intervention for Patients With ST-Elevation Myocardial Infarction: An Update of the 2011 ACCF/AHA/SCAI Guideline for Percutaneous Coronary Intervention and the 2013 ACCF/AHA Guideline for the Management of ST-Elevation Myocardial Infarction. Journal of the American College of Cardiology 2016, 67(10):1235-1250.

7. Brar SS, Aharonian V, Mansukhani P, Moore N, Shen AY, Jorgensen M, Dua A, Short L, Kane K: Haemodynamic-guided fluid administration for the prevention of contrast-induced acute kidney injury: the POSEIDON randomised controlled trial. Lancet 2014, 383(9931):1814-1823.

8. Su X, Xie X, Liu L, LV J, Song F, Perkovic V, Zhang H: Comparative Effectiveness of 12 Treatment Strategies for Preventing Contrast-Induced Acute Kidney Injury: A Systematic Review and Bayesian Network Metaanalysis. American journal of kidney diseases: the official journal of the National Kidney Foundation 2017, 69(1):69-77.

9. Lee HC, Chuang KI, Lu CF, Chiang Y, Wang HJ, Hsieh KL: Use of Contrast Medium Volume to Guide Prophylactic Hydration to Prevent Acute Kidney Injury After Contrast Administration: A Meta-Analysis. AJR American journal of roentgenology 2020, 215(1):15-24.

10. Kushner FG, Hand M, Smith SC, Jr., King SB, 3rd, Anderson JL, Antman EM, Bailey SR, Bates ER, Blankenship JC, Casey DE, Jr. et al: 2009 focused updates: ACC/AHA guidelines for the management of patients with STelevation myocardial infarction (updating the 2004 guideline and 2007 focused update) and ACC/AHA/SCAI guidelines on percutaneous coronary intervention (updating the 2005 guideline and 2007 focused update) a report of the American College of Cardiology Foundation/American Heart Association Task Force on Practice Guidelines. Journal of the American College of Cardiology 2009, 54(23):2205-2241.

11. Ineid $H$, Anderson JL, Wright RS, Adams CD, Bridges CR, Casey DE, Jr., Ettinger SM, Fesmire FM, Ganiats TG, Lincoff AM et al: 2012 ACCF/AHA focused update of the guideline for the management of patients with unstable angina/non-ST-elevation myocardial infarction (updating the 2007 guideline and replacing the 2011 focused update): a report of the American College of Cardiology Foundation/American Heart Association Task Force on Practice Guidelines. Journal of the American College of Cardiology 2012, 60(7):645-681.

12. Aguiar-Souto P, Ferrante G, Del Furia F, Barlis P, Khurana R, Di Mario C: Frequency and predictors of contrast-induced nephropathy after angioplasty for chronic total occlusions. International journal of cardiology 2010, 139(1):68-74.

13. van der Molen AJ, Reimer P, Dekkers IA, Bongartz G, Bellin MF, Bertolotto M, Clement O, Heinz-Peer G, Stacul F, Webb JAW et al: Post-contrast acute kidney injury - Part 1: Definition, clinical features, incidence, role of contrast medium and risk factors: Recommendations for updated ESUR Contrast Medium Safety Committee guidelines. European radiology 2018, 28(7):2845-2855.

14. Marashizadeh A, Sanati HR, Sadeghipour P, Peighambari MM, Moosavi J, Shafe O, Firouzi A, Zahedmehr A, Maadani M, Shakerian F et al: Left ventricular end-diastolic pressure-guided hydration for the prevention of contrast-induced acute kidney injury in patients with stable ischemic heart disease: the LAKESIDE trial. Int Urol Nephrol 2019, 51(10):1815-1822.

15. Khera S, Kolte D, Aronow WS, Palaniswamy C, Mujib M, Ahmed A, Chugh SS, Balasubramaniyam N, Edupuganti M, Frishman WH et al: Trends in acute kidney injury and outcomes after early percutaneous coronary intervention in patients $\geq 75$ years of age with acute myocardial infarction. Am J Cardiol 2013, 112(9):1279-1286.

16. Qian G, Fu Z, Guo J, Cao F, Chen Y: Prevention of Contrast-Induced Nephropathy by Central Venous Pressure-Guided Fluid Administration in Chronic Kidney Disease and Congestive Heart Failure Patients. JACC Cardiovasc Interv 2016, 9(1):89-96.

17. Maioli M, Toso A, Leoncini M, Musilli N, Grippo G, Ronco C, McCullough PA, Bellandi F: Bioimpedance-Guided Hydration for the Prevention of ContrastInduced Kidney Injury: The HYDRA Study. Journal of the American College of Cardiology 2018, 71(25):2880-2889.

18. Mehran R, Aymong ED, Nikolsky E, Lasic Z, lakovou I, Fahy M, Mintz GS, Lansky AJ, Moses JW, Stone GW et al: A simple risk score for prediction of contrast-induced nephropathy after percutaneous coronary intervention: development and initial validation. J Am Coll Cardiol 2004, 44(7):1393-1399.

19. O'Gara PT, Kushner FG, Ascheim DD, Casey DE, Jr., Chung MK, de Lemos JA, Ettinger SM, Fang JC, Fesmire FM, Franklin BA et al: 2013 ACCF/AHA guideline for the management of ST-elevation myocardial infarction: a report of the American College of Cardiology Foundation/American Heart Association Task Force on Practice Guidelines. Circulation 2013, 127(4):e362-425.

20. Windecker S, Kolh P, Alfonso F, Collet JP, Cremer J, Falk V, Filippatos G, Hamm C, Head SJ, Jüni P et al: 2014 ESC/EACTS Guidelines on myocardial revascularization: The Task Force on Myocardial Revascularization of the European Society of Cardiology (ESC) and the European Association for Cardio-Thoracic Surgery (EACTS)Developed with the special contribution of the European Association of Percutaneous Cardiovascular Interventions (EAPCI). European heart journal 2014, 35(37):2541-2619.

21. James MT, Ghali WA, Tonelli M, Faris P, Knudtson ML, Pannu N, Klarenbach SW, Manns BJ, Hemmelgarn BR: Acute kidney injury following coronary angiography is associated with a long-term decline in kidney function. Kidney international 2010, 78(8):803-809.

22. Briguori C, Visconti G, Focaccio A, Airoldi F, Valgimigli M, Sangiorgi GM, Golia B, Ricciardelli B, Condorelli G: Renal Insufficiency After Contrast Media Administration Trial II (REMEDIAL II): RenalGuard System in high-risk patients for contrast-induced acute kidney injury. Circulation 2011, 124(11):1260-1269.

\section{Publisher's Note}

Springer Nature remains neutral with regard to jurisdictional claims in published maps and institutional affiliations. 